\title{
Analysis and Reference for Chinese International Transmission from a Historical Perspective
}

\author{
Gan Huang \\ Beijing International Studies University \\ Beijing, China
}

\author{
Lin Zhu* \\ Beijing International Studies University \\ Beijing, China \\ *Corresponding Author
}

\begin{abstract}
From the perspective of language spread, the author analyzes the language transmission path in "Empires of the Word". This paper analyzes the differences between "Farmer's Approach" and "Hunter's Way" and "Land Language" and "Ocean language". All types of languages have their advantages and disadvantages. Different social activities will have different effects on language spread; this paper discusses how to deal with language and population, language and trade, language and education and other issues.
\end{abstract}

Keywords-language development; language transmission; language and population migration; language and trade

\section{INTRODUCTION}

Language is the genes of a nation; the language is produced during the human evolution. It is a way of communication and a sign of identity. Thus, the development of languages reflects the change of thought, especially the change of identity. We can foresee the future of a language by exploring the mystery of its development and spreading. What a language is like and why it is like that, the answer to both can be found in its history. However, the law of language transmission is not as clear as expected, and the direction it follows is not absolute either which means that the destiny of a language is affected by more than just a single factor, which makes it even more complicated.

\section{The Path Of LANGUaGe SPREAD}

There are two main paths of language spread: land and sea. The Languages by Land include Akkadian, Aramaic, Arabic, in the Middle East, and Egyptian in Africa, Chinese and Sanskrit in Asia, as well as Greek, Latin in Europe and so on. The Languages by Sea or Ocean Languages include Spanish, Portuguese, Dutch, French, Russian, German, Japanese and English. The difference between the two transmission paths is mainly due to the limitation of the transportation which is relative to the science and technology in those periods. The change from the Land Language to Ocean Language is the historical leap and breakthrough that humans conquer geographical restrictions to spread their languages to wider fields.

The difference between the Land Languages and the Ocean Languages is mainly in the span of transmission: The former spread near where they are, and the latter reach a further ground. As a result, they meet different obstacles and troubles on cultures and languages when facing the indigenous people. The Land Languages spread around where they are and in fact, the surrounding areas have a long-term engagement, which means there would be fewer barriers in culture and languages. The Ocean Language transmits overseas; their communication is sudden and relatively short, so there are more conflicts because of the lack of harmony and tolerance on cultural differences and languages. Compared on their driving force of transmission, the Land Languages spread mainly relies on the historical and cultural heritage of the groups behind the languages, which makes the surrounding groups willing to learn from them and integrate; therefore this transmission develops slowly but stably. It helps communities obtain profit, especially resources and markets that the ocean languages develop; some language communities specifically develop policies for the spread of their own language. In the "Empires of the Word", the ocean languages are "In the Train of Empire", in essence, which unveil the fact that the ocean languages develop through the expansion and colonization of empires.

\section{The Language Transmission Path Analysis}

\section{A. Farmer's Approach}

The expansion of a language community is the development of the language in a broad sense. "The most straightforward way in which a language can come to flourish could be called the Farmer's Approach. [1] 13" The essence of this mode of language spread is that the language community works together, enhances their population, and develops the community into a bigger one. In this mode of development, the language community stays in their old territory, without taking the initiative to contact other language communities, and it's even impossible for them to communicate with other communities and acquire their languages in the ideal situation. The spread of Chinese in China is a very typical example. In the past thousands of years, there was no large-scale migration to other regions in China, the main population stayed in the Yangtze River valley and the Yellow River valley. Although the residents of this land were invaded and even ruled by other nations, they didn't break the progress of breeding their own clansmen, and also kept hereditary language alive. Farmer's Approach is also called the Organic Growth; it is the main way to 
develop their language for the communities who are selfsufficient. In this way, the audiences of language transmitting are later generations, spreaders and audiences who have often kinship or social relations. The essence of the Farmer's Approach is to develop the nation's population without (or lack of) cross-ethnic, cross-cultural, crosslanguage contradictions. Usually, such language communities occupy an area rich in resources and property, do not need to deliberately explore and open up space for development or to compete with the surrounding ethnic groups.

\section{B. Hunter's Way}

The Hunter's Way's [1] 14 essence is the cross-ethnic language spread, which is the product of interactions between or among language communities. It includes Migration, Diffusion and Infiltration. [1]14

Migration happens when a language community settles into a new region bringing its language at the same time; it's a language spread way which mainly manifests as migrate and in which there's no change of language share in the language community. Diffusion is when a language community does not have large-scale immigration, but they assimilate the people in the language aspect who are in contact with them around them; in other words, it's like a long-term language infection between language communities. Infiltration is like the integration of Migration and Diffusion; it refers that there is a certain scale of language community migration, and the immigrated community does infect other communities with its language.

Hunter's Way is the cross-language and cross-ethnic language spread way, which is the narrow definition of language spread and also the general subject of language development. Hunter's Way must be the main means to spread language in the context of globalization.

In the history of human development, missionary activities always occupied a place, the spread of religion often led to the spread of language. For example, Christian missionaries, who took the mission to civilize other nations, traveled around the world to spread Christianity, at the same time bringing their own language. Obviously, mission plays an important role in the spread of language. As the main way to obtain scarce products, cross-national trade activity is indispensable in various economic activities. As a result, the common language for trading is necessary. Once a country takes the dominant right or has influence on the international business, the language of the country is likely to be widely disseminated. For example, East India Company in India, a group of colonists, played another role; Foreigners would bring advanced technologies and get the most chances and profits while Indians take the initiative to acquire English, in order to make the conditions to obtain the intangible assets of English.

\section{REVELATION}

\section{A. Population is Needed for Language Spread}

Having and raising children is the simplest way to increase the language community's population. Due to differences in the concept of fertility of different nationalities, the proportion of world language use has changed over the past decade, and the proportion of European languages has been declining in general, while the proportion of Arabic has been improved. Correspondingly, the population of Europe rises slowly, and the Arabic immigrants have higher fertility rate than the others, so the population changes are more conducive to the spread of Arabic. If China wants to ensure the proportion of Chinese use, it must be ensured that local fertility is stable, or we can encourage Chinese, no matter where they live, to speak Chinese when educate their children.

\section{B. Seize the Opportunity of the Time}

Trade is an important means of spreading language. Right now, China has launched the Silk Road Economic Belt and 21st Century Maritime Silk Road, whose core value is to promote international commerce along the line. The translation and interpretation is a rigid demand in international trade, which can expand the employment market of foreign language talents and promote their training. The Belt and the Road increase the frequency of activities between China and other countries, making other countries attach importance to China, attach importance to Chinese and learn Chinese, pay attention to the cultivation of Chinese talent. It broadens the scope of Chinese use, increases the learning value of Chinese, and provides a good time to spread Chinese. The Belt and the Road are not only a great opportunity for Confucius Institutes to have a better development, but also a good opportunity to promote Chinese into the national education system.

\section{Religion and Military Make Difference}

Religion and military can influence on language spread in some conditions, and they wouldn't make many differences in the current international environment, but it is still important to keep an eye on them. Religions themselves can also establish identity, and groups with the same religious beliefs are always more united than those who do not believe in the religion. The religious believers are more motivated to learn a religious language. For example, in our country, the Hui people, who believe in Islam usually, are keener to learn Arabic, and even than Uygur, Kazak and other ethnic minorities, who are more like Arabic apparently and usually Mullins. After the colonization movement, the situation of military oppression has disappeared from most people's eye-sight, but there are still some places in the world that are under the threat of armed forces which control the language use, education and politics, which shows that the armed forces still have a direct impact on language spread. If we want to have a peaceful and stable environment to spread Chinese, the considerable military is needed, to avoid crisis. 


\section{Education is Particularly Important}

The education system makes the most contribution on language spread; as we know, language courses occupy a big part in basic education, and they are also important for further education. Language education is not to merely teach language knowledge but offer an access to the profiles of other nations, which can be added to students' impression or prejudice on the nations. So we should pay attention to students' Chinese education and foreign language education. In China, students should study Chinese language well first and have the ability to express their ideas with normal Chinese and accurate words, then study foreign languages well to touch the world outside. In overseas, we can support and promote Chinese, as a second language, so that the Chinese test can participate in the education system, which will be better for Chinese spread overseas.

\section{CONCLUSION}

As we can see, language can spread by land or by sea. The difference between these two paths is mainly influenced by a historical factor that is the limitation of the vehicle. Language spread by any of the two paths isn't mainly based on the increase of the population of the language community. Most language communities whose members speak these languages face the challenges of touching other communities, or the crisis of imbalanced resource or meager resource, both tangibles and intangibles. In fact, these challenges or crisis are common, in the context of globalization, and every language community must consider the issue. If a community wants to develop well and wants their language spread, it must make good use of the two traditional paths and the new path; the Internet.

The history of language is the history of mankind, the history of the natural development of language, the history of language change, the history of national thought and the epitome of the future language situation. From "Land Language" to "Ocean language", the specific way of language spread does not change much, but the competition among languages is becoming more and more intense. As seen in the functions of Farmer Approach and Hunter's Way, a language community who wants its language to stand out in the troop of languages, needs to ensure the growth of its nation's population - even though it cannot rely solely on it - and take certain measures to make other people learn the language. Considering the spread range and the modern technology, the Internet can be very helpful for language spread. Also, in view of the specific factors affecting the spread of language, we should pay attention to religion and military forces, actively participate and promote international trade, strengthen national constructions, and to make more efforts in science, technology, culture and education.

\section{ACKNOWLEDGEMENT}

This research was financially supported by the National Social Science Foundation of China (Grant NO. 15BYY054), which is "The study of American's Chinese Communication Situation, Problems and Enlightenment". The study of the project received the guidance and help of Professor Zhu Lin.

\section{REFERENCES}

[1] Nicholas Ostler, Empires of the Word: A Language History of the World, Zhang Lu, Fan Fei, Jiang Zhejie, Wang Caoqian, translated, Shanghai: People's Publishing House, 2016.

[2] Abram de Swaan, Words of the World: The Global Language System, Qiao Xiufeng, translated, Guangzhou: Huacheng Publishing House, 2008.

[3] Jianqin Wang, the Belt and the Road and Chinese Spread: Historical Thinking, Current Opportunity and Strategic Planning, Chinese Journal of Language Policy and Planning, vol. 2, pp.33-38, 2016. 